\title{
High Temperature Capacitor Development
}

Final Scientific/Technical Report

For the Period

September 19, 2006 to June 30, 2009

\author{
Prepared by: \\ John A. Kosek, Ph.D., Project Director \\ Phone: (781) 529-0505; Fax: (781) 893-6470 \\ jkosek@ginerinc.com
}

September 25, 2009

Work Performed Under

Cooperative Agreement No. DE-FC26-06NT42945

GINER, INC.

89 Rumford Avenue

Newton, MA 02466-1311

Prepared for:

\section{U.S. DEPARTMENT OF ENERGY}

NATIONAL ENERGY TECHNOLOGY LABORATORY

3610 Collins Ferry Road

P.O. Box 880

Morgantown, WV 26507-0880 


\section{DISCLAIMER}

"This report was prepared as an account of work sponsored by an agency of the United States Government. Neither the United States Government nor any agency thereof, nor any of their employees, makes any warranty, express or implied, or assumes any legal liability or responsibility for the accuracy, completeness, or usefulness of any information, apparatus, product, or process disclosed, or represents that its use would not infringe privately owned rights. Reference herein to any specific commercial product, process, or service by trade name, trademark, manufacturer, or otherwise does not necessarily constitute or imply its endorsement, recommendation, or favoring by the United States Government or any agency thereof. The views and opinions expressed herein do not necessarily state or reflect those of the United States Government or any agency thereof." 


\begin{abstract}
The absence of high-temperature electronics is an obstacle to the development of untapped energy resources (deep oil, gas and geothermal). US natural gas consumption is projected to grow from 22 trillion cubic feet per year (tcf) in 1999 to 34 tcf in 2020. Cumulatively this is 607 tcf of consumption by 2020, while recoverable reserves using current technology are 177 tcf. A significant portion of this shortfall may be met by tapping deep gas reservoirs. Tapping these reservoirs represents a significant technical challenge. At these depths, temperatures and pressures are very high and may require penetrating very hard rock. Logistics of supporting $6.1 \mathrm{~km}(20,000 \mathrm{ft})$ drill strings and the drilling processes are complex and expensive. At these depths up to $50 \%$ of the total drilling cost may be in the last $10 \%$ of the well depth. Thus, as wells go deeper it is increasingly important that drillers are able to monitor conditions down-hole such as temperature, pressure, heading, etc.

Commercial off-the-shelf electronics are not specified to meet these operating conditions. This is due to problems associated with all aspects of the electronics including the resistors and capacitors. With respect to capacitors, increasing temperature often significantly changes capacitance because of the strong temperature dependence of the dielectric constant. Higher temperatures also affect the equivalent series resistance (ESR). High-temperature capacitors usually have low capacitance values because of these dielectric effects and because packages are kept small to prevent mechanical breakage caused by thermal stresses. Electrolytic capacitors do not operate at temperatures above $150^{\circ} \mathrm{C}$ due to dielectric breakdown.
\end{abstract}

The development of high-temperature capacitors to be used in a high-pressure hightemperature (HPHT) drilling environment was investigated. These capacitors were based on a previously developed high-voltage hybridized capacitor developed at Giner, Inc. in conjunction with a unique high-temperature electrolyte developed during the course of the program.

During this program the feasibility of operating a high voltage hybridized capacitor at $230^{\circ} \mathrm{C}$ was demonstrated. Capacitor specifications were established in conjunction with potential capacitor users. A method to allow for capacitor operation at both ambient and elevated temperatures was demonstrated. The program was terminated prior to moving into Phase II due to a lack of cost-sharing funds. 


\section{TABLE OF CONTENTS}

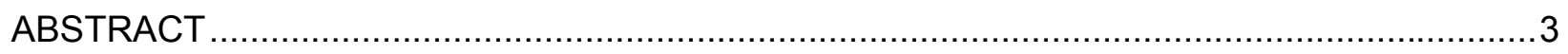

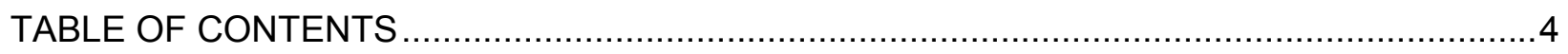

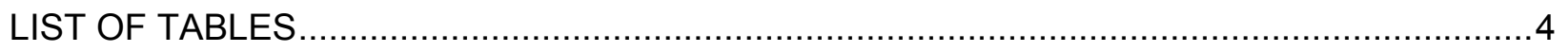

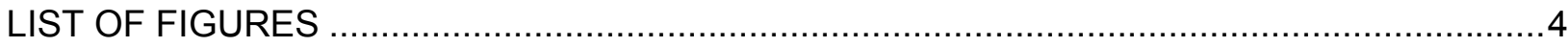

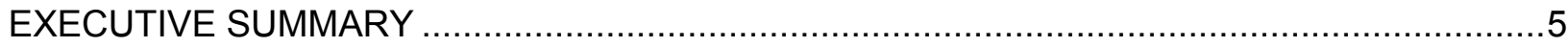

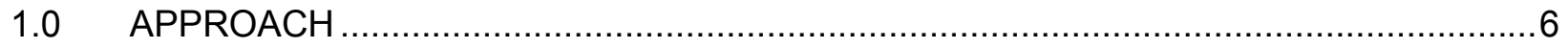

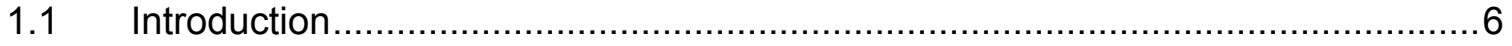

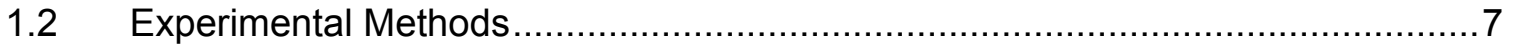

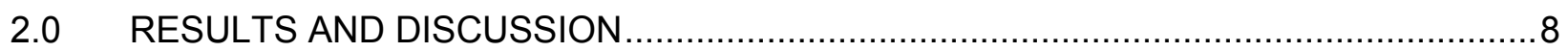

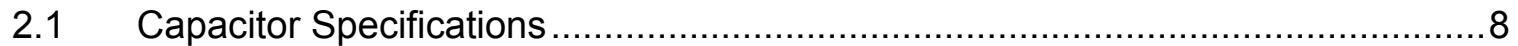

$2.2 \quad$ High Temperature Capacitor Fabrication and Testing................................... 9

2.2.1 Baseline Capacitors ......................................................................... 9

2.2.2 Hybridized Capacitors ....................................................................... 9

2.2.3 Finalized Design, HTHV Hybridized Capacitor ....................................13

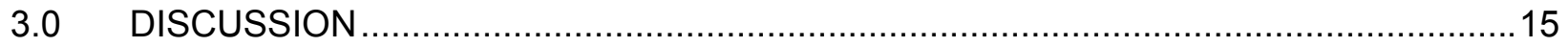

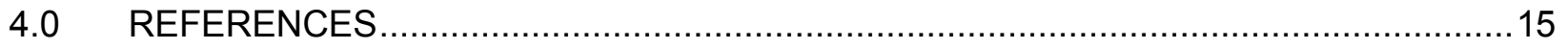

5.0 LIST OF ACRONYMS AND ABBREVIATIONS ..............................................16

\section{LIST OF TABLES}

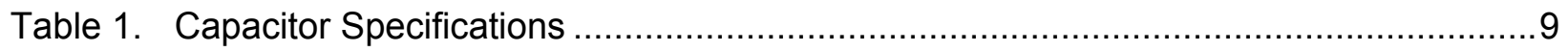

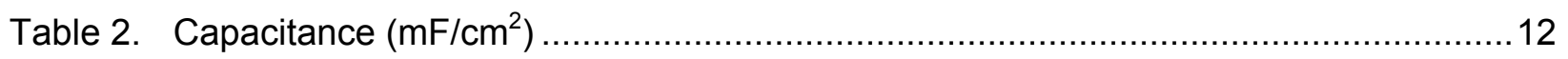

Table 3. Capacitance Measured with Various Electrolytes............................................... 13

Table 4. Comparison of HTE Performance with and without ATE ..................................... 14

\section{LIST OF FIGURES}

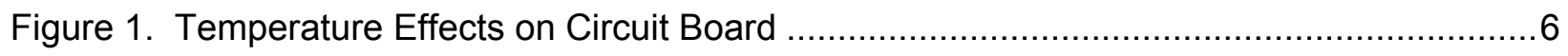

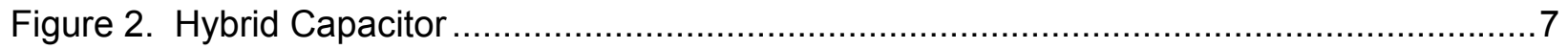




\section{EXECUTIVE SUMMARY}

This project was focused on the development of high-temperature capacitors to be used in a high-pressure high-temperature (HPHT) drilling environment. These capacitors were based on a previously developed high-voltage hybridized capacitor developed at Giner, Inc. in conjunction with a unique high-temperature electrolyte developed during the course of the program. A threephase program was proposed, with only Phases I and II being funded. The program objectives were as follows:

During Phase I, Giner, Inc. proposed the development of a high-temperature, high-voltage allsolid electrochemical-electrolytic capacitor, yielding a low ESR device capable of operation at temperatures up to $232^{\circ} \mathrm{C}$ and at pressures exceeding 137.9MPa. Specific Phase I objectives included:

- Initial investigations to modify the internal anode structure and porosity of the tantalum anode in order to accommodate high-temperature electrolyte within the pore structure.

- Low-cost, highly conductive high-temperature electrolyte materials will be developed and identified.

- Various innovative techniques will be used to improve the electrode-electrolyte interface contact in order to lower the ESR and utilize the surface of the electrode.

- High-temperature high-voltage all-solid electrochemical-electrolytic capacitor cells will be fabricated and characterized/tested to demonstrate the feasibility of our approach.

The technical objectives for the Phase II development program included:

- Miniaturization of the overall high-temperature capacitor footprint

- Based on the Phase I results and input, further refinement to improve capacitor performance, if necessary, which include materials and procedures

- Packaging options and packaging design specifications for the development of the capacitor

- Fabrication of prototype devices for use in the deep drilling applications.

- Conduct laboratory tests to demonstrate and validate performance including energy storage and discharge, unattended operation, heat buildup and dissipation, and endurance.

Technical objectives for the Phase III program included:

- Fabrication of a sufficient quantity of high-temperature capacitors for field testing

- Field testing of the high-temperature capacitors in a downhole environment

The key findings from this program were as follows:

- The feasibility of operating a high voltage hybridized capacitor at $230^{\circ} \mathrm{C}$ was demonstrated.

- $\quad$ Capacitor specifications were established in conjunction with potential capacitor users.

- A method to allow for capacitor operation at both ambient and elevated temperatures was demonstrated.

The program was terminated prior to moving into Phase II due to a lack of cost-sharing funds. 


\subsection{APPROACH}

\subsection{Introduction}

The absence of high-temperature electronics is an obstacle to the development of untapped energy resources (deep oil, gas and geothermal). US natural gas consumption is projected to grow from 22 trillion cubic feet per year (tcf) in 1999 to 34 tcf in 2020. Cumulatively this is 607 tcf of consumption by 2020, while recoverable reserves using current technology are $177 \mathrm{tcf}$. A significant portion of this shortfall may be met by tapping deep gas reservoirs. Tapping these reservoirs represents a significant technical challenge. At these depths, temperatures and pressures are very high and may require penetrating very hard rock. Logistics of supporting $6.1 \mathrm{~km}(20,000 \mathrm{ft})$ drill strings and the drilling processes are complex and expensive. At these depths up to $50 \%$ of the total drilling cost may be in the last $10 \%$ of the well depth. Thus, as wells go deeper it is increasingly important that drillers are able to monitor conditions down-hole such as temperature, pressure, heading, etc. (Mallison et al., 2005).

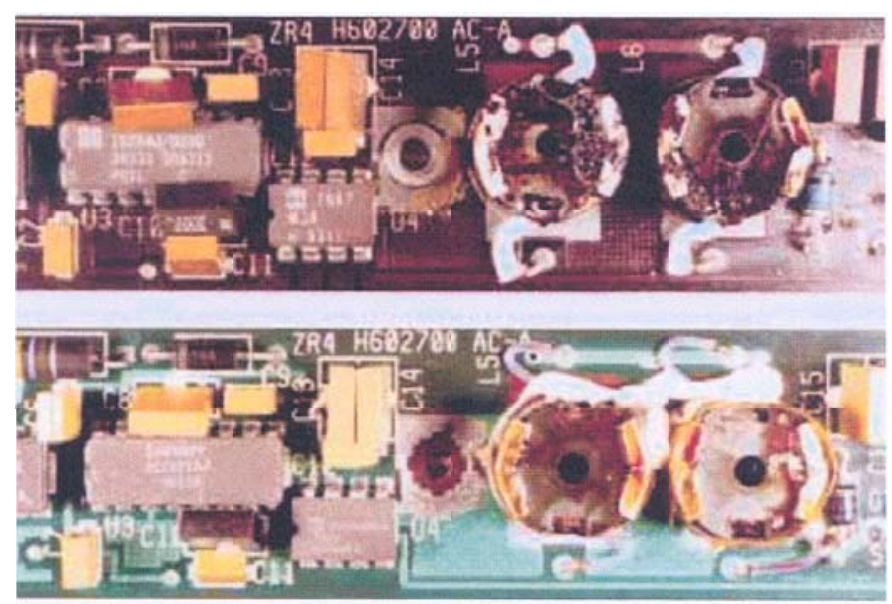

Figure 1. Temperature Effects on Circuit Board

Commercial off-the-shelf electronics are not specified to meet these operating conditions. This is due to problems associated with all aspects of the electronics including the resistors and capacitors. Figure 1 shows the effect of temperature on logging tool circuits. The top scorched circuit board was mounted on a tool exposed to a $177^{\circ} \mathrm{C}\left(350^{\circ} \mathrm{F}\right)$ bottomhole temperature while the bottom circuit board is new (from Baird et al., 1998). With respect to capacitors, increasing temperature often significantly changes capacitance because of the strong temperature dependence of the dielectric constant. Higher temperatures also affect the equivalent series resistance (ESR). High-temperature capacitors usually have low capacitance values because of these dielectric effects and because packages are kept small to prevent mechanical breakage caused by thermal stresses. Electrolytic capacitors do not operate at temperatures above $150^{\circ} \mathrm{C}$ due to dielectric breakdown.

Conventional logging tools (rated to $177^{\circ} \mathrm{C}$ and $137.9 \mathrm{MPa}(20,000 \mathrm{psi})$ ) are upgraded to hightemperature specifications by installing all sensitive electronics in a $137.9 \mathrm{MPa}$ pressure rated Dewar flask housing. The Dewar flask protects the electronic circuits from excessive borehole temperatures. However, weight becomes a concern in high pressure, high temperature (HPHT) wells because the flasks add weight to long combinations of tools. Inside the Dewar, the temperature will increase slowly as there is no way to dissipate the heat generated by the electronics itself. After a sufficiently long time period, the temperatures inside and outside of the Dewar may be comparable.

To overcome some of the problems of the electronics, Giner, Inc. will develop high-temperature capacitors for use on the circuit boards used by the logging equipment. In a Deep Trek Workshop held in March 2001, electronic assemblies that operate at temperatures $>177^{\circ} \mathrm{C}$ were identified as Priorities 2 and 3. Capacitors with ratings of $100 \mu \mathrm{F}, 100$ volts were included in this category. Subsequent studies have identified a specification of $200 \mu \mathrm{F}, 100 \mathrm{~V}$. The hightemperature capacitors will be based on a unique electrolyte to be developed by Giner, Inc. This work will be conducted in conjunction with Evans Capacitor Company, a commercial 
manufacturer of specialty capacitors. In addition, both Baker-Hughes and Schlumberger have expressed an interest in field testing the final device.

\subsection{Experimental Methods}

Giner, Inc. has recently developed a high-voltage all-solid electrochemical-electrolytic capacitor. This capacitor is similar in concept to the liquid acid Hybrid® Capacitor (Registered Trademark, Evans Capacitor Corp.) developed by Evans (Evans, 1994) except the Giner, Inc. capacitor uses a solid polymer electrolyte ionomer (i.e. Nafion) within and between the porous positive (anode) and negative (cathode) electrode structures. This capacitor combines an electrochemical capacitor cathode and an electrolytic capacitor anode. By employing a dielectric anode electrode, the single-cell hybrid capacitor is able to withstand high breakdown voltages. A tento-one improvement in energy density compared to state-of-the-art aluminum electrolytic capacitors with comparable electrical performance has been achieved in liquid acid hybrid capacitors using a tantalum anode, sulfuric acid electrolyte, and a $\mathrm{RuO}_{2}$ cathode (Evans, 1995). Because of their relatively smaller size, hybrid capacitors also have higher power densities than electrolytic capacitors. Liquid acid hybrid tantalum capacitors are manufactured in a variety of configurations. Capacitances of $100 \mu \mathrm{F}-200 \mathrm{mF}$ and voltage ratings of 3-125V are available. A high-voltage all-solid electrochemical-electrolytic capacitor cell is shown in Figure 2.

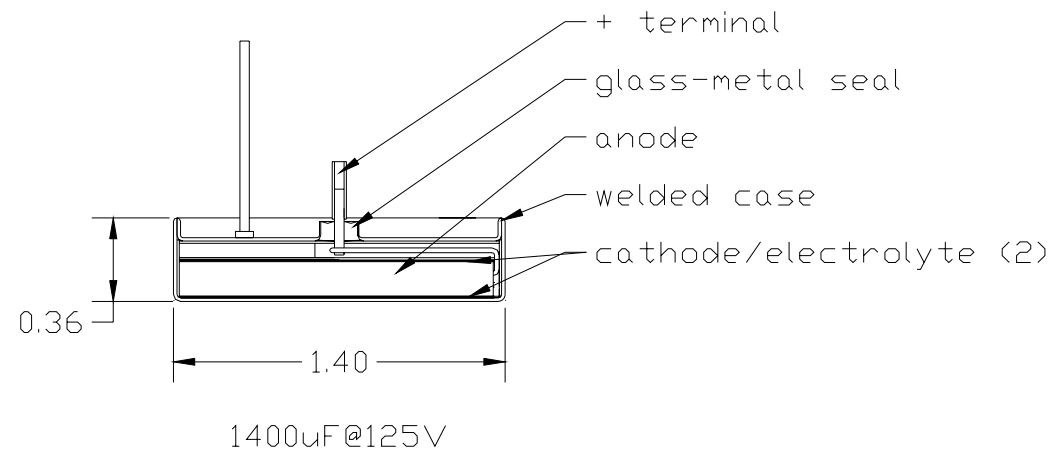

Figure 2. Hybrid Capacitor

The anode in a tantalum high-voltage electrochemical-electrolytic capacitor is comprised of a sintered slug of commercially available capacitor grade tantalum powder which is electrochemically oxidized, coating the surface with $\mathrm{Ta}_{2} \mathrm{O}_{5}$ dielectric material. The density of the slug is controlled during manufacture to be in the range of $30-35 \%$ of theoretical tantalum density $\left(\sim 5 \mathrm{~g} / \mathrm{cm}^{3}\right)$. This leads to a highly porous structure with a large surface area. The weight of the slug and the formation voltage determine the capacitance and voltage rating of the anode. The cathode is thermally prepared $\mathrm{RuO}_{2}$ bonded to a thin metal foil. Because of its high capacitance density, the amount of $\mathrm{RuO}_{2}$ needed is relatively small, on the order of $2-4 \mathrm{mg} / \mathrm{cm}^{2}$ of cathode area. The cathode capacitance density is usually about $50 \mathrm{mF} / \mathrm{cm}^{2}$. The total thickness of the cathode, including the foil substrate is $50-100 \mu \mathrm{m}$. As long as the magnitude of the cathode capacitance is sufficiently high, the performance of the capacitor depends exclusively on the performance of the $\mathrm{Ta}_{2} \mathrm{O}_{5}$ anode.

Giner, Inc. will develop an all solid or immobilized electrolyte high-voltage electrochemicalelectrolytic capacitor for high-temperature operation, yielding a low-cost, low ESR device. The negative electrode or cathode will be made from highly conductive stabilized metal oxide (particulate formed $\mathrm{RuO}_{\mathrm{x}}$ ) while the positive electrode or anode will be made from a pressed tantalum particulate electrode, modified to have enhanced porosity and $\mathrm{Ta}_{2} \mathrm{O}_{5}$ barrier oxide. The challenge is to modify the internal structure and porosity of the tantalum anode to 
accommodate the high-temperature electrolyte within the anode pore structure. The specific innovative concept is the development of an all-solid high-voltage capacitor in conjunction with a high-temperature electrolyte by combining the modified porous tantalum oxide structure of a high-voltage electrolytic type anode with a low-voltage, high-energy-density electrochemical redox pseudocapacitance cathode. It combines the advantages of the electrochemical capacitor (i.e. high energy density, high power density) and the electrolytic capacitor (i.e. low ESR, high voltage rating) to provide efficient power transfer for the given application.

Anodes are fabricated using standard methods. A known quantity of Ta powder (H.C. Stark No. NA30KN) is placed in a pressing die. The powder is then compacted under pressure in a Carver Press to form a pellet. The pellet is sintered under high vacuum ( $<3 \times 10-6$ torr) at elevated temperature for 20 minutes. After cooling to room temperature and removing from the vacuum furnace, the pellet is anodically oxidized in an ethylene glycol/ $\mathrm{H}_{3} \mathrm{PO}_{4}$ mixture to form a layer of $\mathrm{Ta}_{2} \mathrm{O}_{5}$ coating on the Ta surface. Finally the pellet is rinsed several times in distilled water.

Subsequent to anode formation the pellets are imbibed with a solubilized ionomer to impart ionic conductivity to the anode. The solubilized ionomer, in an appropriate solvent, is applied using a pipette, evaporating the solvent between applications. A total of 20 applications are required to form a uniform coating for baseline capacitors.

The capacitor cathode is formed from $\mathrm{RuO}_{\mathrm{x}}$ on a Ti foil collector. A known quantity of $\mathrm{RuO}_{\mathrm{x}}$ (Aesar, No. 11803) is mixed with a low boiling point organic liquid. The Ti foil is placed on a hotplate and, using a pipette, layers of $\mathrm{RuO}_{\mathrm{x}}$ are built up on the $\mathrm{Ti}$ foil by applying a layer of $\mathrm{RuO}_{x}$, allowing the solvent to evaporate, followed by addition of another layer.

Capacitance was measured by charging the capacitors to a set voltage and discharging across a $48 \Omega$ load while recording the discharge potential vs. time. The RC time constant of the capacitor was taken as the time of the voltage decay from $90 \%$ of maximum voltage $\left(V_{1}\right)$ to $V_{1} / e$. Capacitance is equal to the RC time constant divided by the load resistance, ohms. The capacitors were charged with a XANTREX model XHR600-1 DC power supply and the discharge curves were recorded on a computer using LabTech Notebook data acquisition software.

Electrical impedance measurements were made with an EG\&G Model 263 A potentiostat and an EG\&G Model 5210 lock-in-amplifier. A 10-mV sine wave was applied at frequencies ranging from $1 \mathrm{~Hz}$ to $100 \mathrm{kHz}$. The real and imaginary impedance components, $Z_{R E}$ and $Z_{I M}$ were used to evaluate resistance.

\section{$2.0 \quad$ RESULTS AND DISCUSSION}

\subsection{Capacitor Specifications}

In order to generate specifications for the capacitors to be developed on this program, requests were made to several drilling companies for specifications of the capacitors that they currently use for drilling applications. Responses were not received. In order to obtain information so that realistic capacitor specifications could be generated, the NETL Program Manager suggested conducting a survey of various users, to determine their needs and wants. A survey was prepared, submitted to NETL, and then distributed by NETL to various users.

A total of 5 responses were received to the survey. Based on feedback to the survey, the following capacitor specifications, summarized in Table 1, were generated for both the capacitor electrical characteristics and physical size. 
No specification was established for mechanical vibrations. Input for this parameter ranged from "compliant lead frames" to "handle shock of truck transport" to "high impact shock $20,000 \mathrm{~g}$, $50 \mu \mathrm{S}$ ".

Table 1. Capacitor Specifications

\begin{tabular}{|l|c|}
\hline \multicolumn{1}{|c|}{ Parameter } & Specification \\
\hline Capacitance $(\mu \mathrm{F})$ & 220 \\
\hline Voltage $(\mathrm{V})$ & 100 \\
\hline Operating Temperature $\left({ }^{\circ} \mathrm{F}\left({ }^{\circ} \mathrm{C}\right)\right)$ & $450(232)$ \\
\hline Outside Diameter (inches $(\mathrm{cm}))$ & $1(2.56)$ \\
\hline Length, excluding leads (inches $(\mathrm{cm}))$ & $1(2.56)$ \\
\hline
\end{tabular}

\subsection{High Temperature Capacitor Fabrication and Testing}

\subsubsection{Baseline Capacitors}

To verify electrolyte suitability for high temperature operation, conventional capacitors consisting of $\mathrm{RuO}_{\mathrm{x}}$ for both the anode and cathode were fabricated. These capacitors had a 1$\mathrm{cm}^{2}$ active area. Prior to testing with the high temperature electrolyte (HTE), the capacitors were tested using a sulfuric acid electrolyte by both $A C$ impedance and $D C$ discharge. For the $A C$ impedance testing, measured capacitances were $11.3,6.0,0.9 \mathrm{mF} / \mathrm{cm}^{2}$ at $10,100,1 \mathrm{kHz}$ respectively, and an ESR $=0.6 \mathrm{ohms}$. The capacitor was charged to $1 \mathrm{~V}$ and discharged through a $48 \Omega$ resistor, yielding a capacitance of $18.0 \mathrm{mF} / \mathrm{cm}^{2}$. The electrodes were rinsed, filled with the high temperature electrolyte and tested by $A C$ impedance at $200,250,300^{\circ} \mathrm{C}$. Performance was poor with a very high resistance.

Several additional capacitors were fabricated using $\mathrm{RuO}_{\mathrm{x}}$ for both electrodes and the HTE as the capacitor electrolyte. These capacitors were placed in a Ta clip holder and tested by both $\mathrm{AC}$ impedance and $\mathrm{DC}$ discharge at temperatures ranging from 50 to $350^{\circ} \mathrm{C}$ in $50^{\circ} \mathrm{C}$ increments. At the low temperatures the capacitors exhibited high resistance and low capacitance. At $250^{\circ} \mathrm{C}$ the highest capacitance (measured at $100 \mathrm{kHz}$ by AC impedance) was $168 \mathrm{mF} / \mathrm{cm}^{2}$, with a resistance of $96 \mathrm{~m} \Omega$. When tested by DC discharge across a $48 \Omega$ load (charging to1V) the best capacitance was $633 \mathrm{mF} / \mathrm{cm}^{2}$.

These tests demonstrated that the HTE was capable of $250^{\circ} \mathrm{C}$ operation.

\subsubsection{Hybridized Capacitors}

Hybridized capacitors were fabricated using $\mathrm{Ta}_{2} \mathrm{O}_{5}$ anodes and $\mathrm{RuO}_{\mathrm{x}}$ cathodes. To expedite cathode fabrication, cathodes were procured from Evans Capacitor Corp. This allowed us to utilize a pre-made production cathode in our capacitor. Since this was a production item, it was expected to be more uniform than individual cathodes fabricated at Giner, Inc. The anodes and cathodes were charged with HTE, formed into high-temperature, high-voltage (HTHV) hybridized capacitors, and tested by both $\mathrm{AC}$ impedance and DC discharge at temperatures up to $250^{\circ} \mathrm{C}$.

Capacitance, measured by AC impedance, on most capacitors was low, on the order of $80 \mu \mathrm{F}$ at $100 \mathrm{~Hz}$ at $250^{\circ} \mathrm{C}$. When tested by DC discharge the capacitors would not charge above $70 \mathrm{~V}$. As the capacitor voltage goal was $100 \mathrm{~V}$, various methods to achieve this voltage were evaluated. 


\subsubsection{Methods to Increase Capacitor Voltage}

When the high-temperature capacitors were tested at temperatures above $200^{\circ} \mathrm{C}$, they could only be charged to a maximum of $70 \mathrm{~V}$. Efforts were spent evaluating methods to increase the capacitor voltage. A number of capacitor variations were fabricated and tested; these are described in more detail below. Capacitance was measured by both AC impedance and by charging and discharging the capacitors across a $48 \Omega$ resistor.

High-Voltage Powders: One method to increase the formation voltage to allow higher operating voltage is to change to a lower surface area powder and/or higher sintering temperature. Capacitors were initially fabricated using NA30KN tantalum powder for the anode. This material was formed into $\mathrm{Ta}_{2} \mathrm{O}_{5}$ using a $150 \mathrm{~V}$ formation voltage. At the suggestion of Evans Capacitor, anodes were fabricated using two different high voltage (lower surface area) Ta powders, QR3 and HVTT. These were formed into $\mathrm{Ta}_{2} \mathrm{O}_{5}$ at 250V. The HVTT disk broke apart. The QR3 disk was filled with HTE and made into a high temperature, high voltage (HTHV) hybridized capacitor with an Evans $\mathrm{RuO}_{\mathrm{x}}$ cathode. The capacitor was tested by an $\mathrm{AC}$ impedance scan and DC discharge. At $100 \mathrm{~Hz}$ capacitance was $35 \mu \mathrm{F}\left(250^{\circ} \mathrm{C}\right)$. By DC discharge at $20 \mathrm{~V}$ and $50 \mathrm{~V}$, capacitance was $\sim 200 \mu \mathrm{F}\left(\sim 80 \mu \mathrm{F} / \mathrm{cm}^{2}\right)$ at $250^{\circ} \mathrm{C}$. However, the capacitor would not charge above $75 \mathrm{~V}$; it would only pass a constant current.

A $\mathrm{Ta}_{2} \mathrm{O}_{5}$ anode was held overnight at $125 \mathrm{~V}$ in $38 \% \mathrm{H}_{2} \mathrm{SO}_{4}$ to try to increase the potential range in a HTHV hybridized capacitor by increasing the oxide thickness. Tested by DC discharge in $\mathrm{H}_{2} \mathrm{SO}_{4}$ at ambient temperature before and after the overnight procedure, capacitance was $688 \mu \mathrm{F},\left(265 \mu \mathrm{F} / \mathrm{cm}^{2}\right)$, and the anode charged to $125 \mathrm{~V}$, although the leakage current at $125 \mathrm{~V}$ increased from 275 to $320 \mu \mathrm{A}$ overnight. The anode was used to make a HTHV hybridized capacitor, filled with melted HTE and paired with an Evans cathode. Tested by DC discharge at $130^{\circ} \mathrm{C}$, the capacitor charged to $125 \mathrm{~V}$ and capacitance decreased to $38 \mu \mathrm{F}\left(14 \mu \mathrm{F} / \mathrm{cm}^{2}\right)$. At $200^{\circ} \mathrm{C}$, it only charged to $\sim 85 \mathrm{~V}(3.0 \mathrm{~mA})$, with a capacitance of $108 \mu \mathrm{F}$. At $250^{\circ} \mathrm{C}$ capacitance was $588 \mu \mathrm{F}$ but it only charged to $\sim 50 \mathrm{~V}$. At $230^{\circ} \mathrm{C}$ it only charged to $\sim 69 \mathrm{~V}$.

Thermal Oxidation: A useful step when making anodes with high formation voltage is a socalled mid-form-anneal step. This involves a soak either in air or vacuum at about $300^{\circ} \mathrm{C}$ for up to an hour. It is thought this step helps rearrange the oxide by oxygen diffusion, making the formation more isotropic. Sometimes, it helps to significantly reduce leakage current. Oxygen migration out of the $\mathrm{Ta}_{2} \mathrm{O}_{5}$ layer into the $\mathrm{Ta}$ base electrode has been suggested before, but we know of no published experimental evidence of this. To evaluate the effect of the mid-formanneal step, or thermal oxide layer, four anodes were fabricated, two with NA30KN Ta powder, and two with HVTT Ta powder. The anodes were kept in a vacuum furnace chamber overnight to cool in argon before removing. For each run, on removal from the vacuum furnace (at $16^{\circ} \mathrm{C}$ ), one anode was immediately put in a beaker of $\mathrm{N}_{2}$, resealed and reflushed with $\mathrm{N}_{2}$. The other was left in open air at room temperature. The $\mathrm{Ta}_{2} \mathrm{O}_{5}$ formation was begun $2.5-3$ hours after removal from the furnace. The NA30KN anodes were formed at $150 \mathrm{~V}$, the HVTT disks formed at $250 \mathrm{~V}$, all were rinsed, boiled and dried. HTHV hybridized capacitors were made with the NA30KN disks, dip-filled with molten HTE, and mated with an Evans cathode.

The HTHV hybridized capacitor that used NA30KN Ta which had been kept in $\mathrm{N}_{2}$ (at room temp) before $\mathrm{Ta}_{2} \mathrm{O}_{5}$ formation had good capacitance in $\mathrm{AC}$ impedance testing and DC discharge tests at 50V, among the best at lower temperatures, but only charged to $60-80 \mathrm{~V}$ at 200,230 , and $250^{\circ} \mathrm{C}$ in DC discharge testing. The HTHV capacitor that used NA30KN Ta that had been kept in air at room temperature before $\mathrm{Ta}_{2} \mathrm{O}_{5}$ formation performed similarly. Likewise, the HTHV hybridized capacitor using an anode fabricated with HVTT Ta that had been kept in $\mathrm{N}_{2}$ at room temperature before $\mathrm{Ta}_{2} \mathrm{O}_{5}$ formation had lower capacitance than the NA30KN disks (as 
expected) but still only went to $60-70 \mathrm{~V}$ at $200^{\circ} \mathrm{C}$. No advantage was observed with the use of a controlled thermal oxide layer.

Separator: An HTHV hybridized capacitor was made with a ceramic felt separator to try to avoid shorting, one possible reason the capacitors could not be charged above 70V. The anode was dip-filled with molten HTE, a $2.54 \mathrm{~mm}$ (0.010 inch) thick porous felt disk was placed over the anode, the felt covered with more HTE, and the Evans $\mathrm{RuO}_{x}$ disk put on top. Tested after cooling, capacitance was low and resistance high; HTE may not have adequately wet the ceramic felt. By RC discharge testing, it only charged to $66 \mathrm{~V}$, with a $10 \mathrm{~mA}$ constant current indicating a partial short.

Mixed Electrolyte: A new HTE variation was tried in an HTHV hybridized capacitor. The anode was filled with molten HTE and a disk of mixed $\mathrm{HTE}$ and $\mathrm{SiP}_{2} \mathrm{O}_{7}, 1: 1$ by weight, was put over the anode, an Evans cathode placed on top, and re-melted to bond. By AC impedance scans, capacitance was $55 \mu \mathrm{F} / \mathrm{cm}^{2}$ at $100 \mathrm{~Hz}$. By RC discharge test the capacitor charged to 73V; $\mathrm{SiP}_{2} \mathrm{O}_{7}$ did not help to increase the voltage.

Alternate Filling Methods: An alternate method was evaluated to fill the anodes with HTE. One $\mathrm{Ta}_{2} \mathrm{O}_{5}$ anode was pre-filled with an aqueous solution of HTE by repeated applications and drying at $120^{\circ} \mathrm{C}$. The other was filled with solution to form the HTE within the disk. Both were dip-filled with molten HTE and placed in a ceramic ring-mold; molten HTE and an Evans cathode disk were added to form the HTHV hybridized capacitor. Both hybridized capacitors were tested by an AC impedance scan and by DC discharge, performance was similar to HTHV hybridized capacitors made by filling with molten HTE; no improvement was observed by prefilling the anodes.

Modified Formation Procedure: In an effort to increase the HTHV hybridized capacitor operating voltage, testing was focused on modifying the $\mathrm{Ta}_{2} \mathrm{O}_{5}$ dielectric. A new $\mathrm{Ta}_{2} \mathrm{O}_{5}$ formation solution was made (Kinard et al, 1999), which reportedly can make $\mathrm{Ta}_{2} \mathrm{O}_{5}$ layers of unlimited thickness. The solution was $10 \mathrm{wt} \%$ dibasic potassium phosphate in glycerol. The solution was heated to and held at $175^{\circ} \mathrm{C}$. A Ta anode disk was installed and $\mathrm{Ta}_{2} \mathrm{O}_{5}$ formation initiated at $20 \mathrm{~V}$ (limit setting). During this process the color of the Ta anode changed from green to deep blue, which may indicate a thicker $\mathrm{Ta}_{2} \mathrm{O}_{5}$ layer.

After formation the Ta disks were filled with HTE, bonded to an Evans cathode and tested. With $\mathrm{DC}$ charging at $20 \mathrm{~mA}$, the capacitors could only be charged to $19 \mathrm{~V}$. Capacitance by RC discharge was high: $223 \mu \mathrm{F} / \mathrm{cm}^{2}$ at $230^{\circ} \mathrm{C}$ and $2931 \mu \mathrm{F} / \mathrm{cm}^{2}$ at $250^{\circ} \mathrm{C}$. An AC impedance test showed high capacitance at high temperature also but with a large drop in capacitance at temperatures at or below $200^{\circ} \mathrm{C}$. A new solution of dibasic potassium phosphate was prepared and used for $\mathrm{Ta}_{2} \mathrm{O}_{5}$ formation on an NA30KN disk at $20 \mathrm{~V}$ and $175^{\circ} \mathrm{C}$.

Another disk was $\mathrm{Ta}_{2} \mathrm{O}_{5}$-formed using a pulse routine, alternating applying $20 \mathrm{~V}$, then open circuit (equal time) with a frequency of $\sim 1 \mathrm{~Hz}$. This procedure produces a more uniform $\mathrm{Ta}_{2} \mathrm{O}_{5}$ thickness within the disk.

All disks prepared above were washed with distilled $\mathrm{H}_{2} \mathrm{O}$, and dried overnight at $110^{\circ} \mathrm{C}$. A high temperature capacitor was made using an anode disk formed in the alternate formation electrolyte. The anode was filled with HTE, then bonded to an Evans cathode disk. The capacitor, tested from room temperature to $250^{\circ} \mathrm{C}$, would only charge to $36 \mathrm{~V}$ at room temp at $10 \mathrm{~mA}$ charging current. At $250^{\circ} \mathrm{C}$, it would only charge to $\sim 10 \mathrm{~V}$. At $250^{\circ} \mathrm{C}$ capacitance (best) 
was only $26 \mu \mathrm{F}$ at $100 \mathrm{~Hz}$ with an ESR of 110 ohms; by RC discharge across a 48 ohm resistor capacitance was $\sim 200 \mu \mathrm{F}$.

A capacitor pretreatment procedure was evaluated to determine if this would improve capacitor performance. The pretreatment procedure will repair any defects in the $\mathrm{Ta}_{2} \mathrm{O}_{5}$ by forming a new oxide. This procedure is performed in $\mathrm{H}_{2} \mathrm{SO}_{4}$ electrolyte and allows the electrodes time to fully wet out with electrolyte. The handling and assembly of tantalum capacitor anodes inevitably causes physical damage to the dielectric, which is repaired in the working electrolyte by forming new oxide. This occurs naturally during the pretreatment procedure. After the process, the leakage current has been reduced by orders of magnitude, the ESR and capacitance have stabilized. Anode disks were prepared and pretreated, but were never tested.

Membrane Electrolytes: Two approaches were evaluated in the development of a hightemperature electrolyte. The first, described above, involved filling both the anode and cathode with HTE. The second approach involved imbibing membranes with phosphoric acid.

A HTHV hybridized capacitor was made with the NA30KN powder, imbibing the anode with solubilized membrane, allowing the solvent to evaporate, and finally soaking in phosphoric acid. The capacitor was tested by AC impedance, with results shown in Table 2.

Table 2. Capacitance $\left(\mathrm{mF} / \mathrm{cm}^{2}\right)$

\begin{tabular}{|l|c|c|c|c|}
\hline & $\underline{\mathbf{1 0 ~ H z}}$ & $\underline{\mathbf{1 0 0 ~ H z}}$ & $\underline{\mathbf{1 K H z}}$ & $\underline{\mathbf{R} \text { (ohms) }}$ \\
\hline Room temp. & 0.223 & 0.0956 & 0.0208 & 3.7 \\
\hline $\mathbf{1 0 0 ^ { \circ } \mathbf { C }}$ & 0.473 & 0.137 & 0.0048 & 6.5 \\
\hline $\mathbf{1 5 0}^{\circ} \mathbf{C}$ & 0.624 & 0.093 & 0.0013 & 8.9 \\
\hline $\mathbf{2 0 0 ^ { \circ } \mathbf { C }}$ & 0.139 & 0.0041 & 0.0005 & 7.8 \\
\hline
\end{tabular}

As the table illustrates, the results were unexpected. The resistance initially increased with temperature and, after $150^{\circ} \mathrm{C}$, began to decrease. The resistance was also higher than that observed with the HTHV hybridized capacitors fabricated using HTE. DC charge and discharge testing was conducted at $200^{\circ} \mathrm{C}$; the capacitor could only be charged to $\sim 50 \mathrm{~V}$.

Another HTHV hybridized capacitor was fabricated, this time using the HVTT Ta powder and the phosphoric acid imbibed membrane. This capacitor could not be charged above 50V.

\subsubsection{Discussion}

Discussions concerning the inability to achieve a high working voltage were held with our partner and consultant, Evans Capacitor Company. According to Evans, as the working temperature increases, the dielectric becomes progressively leakier for reasons related to electron tunneling and not necessarily to imperfections in the dielectric.

At constant voltage, the leakage current increases exponentially with temperature. At some level of current, $I^{2} R$ heating at electron tunneling sites or imperfections raises the local temperature and can cause more defects in the oxide, for instance, thermal conversion of the amorphous oxide to crystalline form. This kind of defect does not "heal" in sulfuric acid and probably will not heal in the HTE. Defects of this type appear as grey oxide.

Even if permanent defects do not occur, the local heating causes a current run away effect, because of the dual exponential relation between current and temperature. The higher the 
temperature goes, the higher the current, and so on. This mechanism leads quickly to breakdown failure.

\subsubsection{Finalized Design, HTHV Hybridized Capacitor}

As discussed above, when the HTHV hybridized capacitors were tested at temperatures above $200^{\circ} \mathrm{C}$, they could only be charged to a maximum of $70 \mathrm{~V}$. A decision was made to limit the capacitor voltage to a maximum of $50 \mathrm{~V}$ and utilize a 2-cell capacitor stack as a means to achieve the $100 \mathrm{~V}$ goal. Variations of the HTE were re-evaluated to determine which electrolyte variation would provide the highest capacitance and lowest resistance at 50V. Capacitance was measured by both $\mathrm{AC}$ impedance and by charging and then discharging the capacitors across a $48 \Omega$ resistor.

$\mathrm{HTHV}$ capacitors were fabricated using $\mathrm{Ta}_{2} \mathrm{O}_{5}$ anodes and $\mathrm{RuO}_{x}$ cathodes. All anode disks were washed with distilled $\mathrm{H}_{2} \mathrm{O}$, and dried overnight at $110^{\circ} \mathrm{C}$. The anode was filled with $\mathrm{HTE}$, and bonded to an Evans cathode disk. Three different high temperature electrolytes were tested; one was the conventional HTE used for the bulk of the testing in this program, one was a modified HTE that incorporated $\mathrm{SiP}_{2} \mathrm{O}_{7}$, and the third was a new HTE, designated HTE-2.

Results of the testing are summarized in Table 3. All values listed in the table are the averages of multiple tests. Testing was conducted at $230^{\circ} \mathrm{C}$, charging the capacitors to a maximum of $50 \mathrm{~V}$. Capacitance values listed in the table are calculated by discharging the capacitor across a 48-ohm resistor.

Table 3. Capacitance Measured with Various Electrolytes

\begin{tabular}{|c|c|c|c|c|}
\hline \multirow{2}{*}{ Electrolyte } & & $25^{\circ} \mathrm{C}$ & \multicolumn{2}{|c|}{$230^{\circ} \mathrm{C}$} \\
\hline & $\begin{array}{c}\text { Voltage } \\
(\mathbf{V})\end{array}$ & $\begin{array}{c}\text { Capacitance } \\
(\boldsymbol{\mu} \mathrm{F})\end{array}$ & $\begin{array}{c}\text { Capacitance } \\
(\boldsymbol{\mu} \mathrm{F})\end{array}$ & $\begin{array}{c}\text { Resistance } \\
(\Omega)\end{array}$ \\
\hline $\mathrm{HTE}-2$ & 50 & 54 & 587 & 14 \\
\hline $\mathrm{HTE}$ & 50 & 43 & 556 & 7 \\
\hline $\mathrm{HTE}-\mathrm{SiP}_{2} \mathrm{O}_{7}$ & 50 & 60 & 794 & 4 \\
\hline \hline $\mathrm{HTE}-\mathrm{SiP}_{2} \mathrm{O}_{7}$ & 100 & 48 & 380 & 7 \\
\hline
\end{tabular}

As can be seen, at elevated temperature, all the single cells had a high capacitance. Resistance, however, was higher than desirable. Room temperature capacitance, however, was quite low, typically only $10 \%$ of that seen at elevated temperature. This was because of the nature of the HTE, which does not become readily conductive until the temperature exceeds $100^{\circ} \mathrm{C}$.

Of the three HTEs tested at $50 \mathrm{~V}$, the $\mathrm{HTE}-\mathrm{SiP}_{2} \mathrm{O}_{7}$ electrolyte was selected to be used in a 2-cell capacitor stack. It was selected based on providing the highest capacitance and lowest resistance of the 3 electrolytes evaluated. A 2-cell stack is typically implemented by placing the 
negative electrode of one capacitor in contact with the positive electrode of the other capacitor. For this testing, however, the capacitor cells were connected in series by means of jumper wires, to allow the capacitance and resistance of the individual cells to be measured.

Capacitance of the 2-cell stack was 380 microfarads, exceeding the Phase 1 goal of 220 microfarads at $100 \mathrm{~V}$. This was achieved with a rather high cell resistance. Lowering the capacitor resistance will allow us to obtain an even higher capacitance, which would then allow the capacitor footprint to be made smaller.

The capacitors used in the above testing were circular in shape, with a positive electrode that was $1.78 \mathrm{~cm}$ (0.7 inch) in diameter. The capacitors were not enclosed in a final package but, based on the physical size of the capacitors, the final package is expected to be significantly thinner than the $2.54 \mathrm{~cm}$ (1 inch) height specified in the goals for this program.

\subsubsection{Capacitor Electrolyte Modifications}

When used in an actual drilling environment, the drilling electronics are tested at ambient temperature prior to insertion of the drill and electronics into the ground. Therefore, the HTHV hybridized capacitor has to operate at ambient temperature. Efforts were directed at improving ambient temperature performance. A literature search was conducted to identify an ambient temperature electrolyte (ATE) that would be compatible with the HTE and would provide adequate conductivity at ambient temperature. Attempts were made to synthesize the electrolyte, which were not successful. A commercial version of the material was purchased and tested.

Apparatus was fabricated to measure the conductivity of the electrolytes as a function of temperature. Duplicates of three different materials were evaluated: the current HTE, a mixture of the ATE and the HTE, and the ATE alone.

Test results were not encouraging. The ambient temperature resistance of all three materials was extremely high. We suspect that the commercial version of the room temperature electrolyte was not in the proper chemical form to allow for ambient temperature conductivity.

A new synthesis route was used to make the ambient temperature electrolyte. Subsequent to synthesis, the material was blended with the current HTE and incorporated into a HTHV hybridized capacitor. Resistance and capacitance were measured at both ambient temperature and elevated temperature. Results summarized in Table 4 are average values from tests on multiple capacitors; leakage currents were also measured.

Table 4. Comparison of HTE Performance with and without ATE

\begin{tabular}{|c|c|c|c|c|c|c|}
\hline Electrolyte & \multicolumn{3}{|c|}{$\mathbf{2 3}^{\circ} \mathbf{C}$} & \multicolumn{3}{|c|}{$\mathbf{2 3 0}^{\circ} \mathbf{C}$} \\
\hline & $\begin{array}{c}\text { Capacitance } \\
(\boldsymbol{\mu} \mathbf{F})\end{array}$ & $\begin{array}{c}\text { Resistance } \\
(\boldsymbol{\Omega})\end{array}$ & $\begin{array}{c}\text { Leakage } \\
\text { Current } \\
(\boldsymbol{\mu A})\end{array}$ & $\begin{array}{c}\text { Capacitance } \\
(\boldsymbol{\mu} \mathbf{F})\end{array}$ & $\begin{array}{c}\text { Resistance } \\
(\boldsymbol{\Omega})\end{array}$ & $\begin{array}{c}\text { Leakage } \\
\mathbf{C u r r e n t} \\
(\boldsymbol{\mu A})\end{array}$ \\
\hline HTE Alone & 60 & $156 \mathrm{~K}$ & $25-69$ & 794 & 4 & $\begin{array}{c}1368- \\
3489\end{array}$ \\
\hline HTE + ATE & 48 & 337 & $38-60$ & 673 & 24 & $553-$ \\
& & & & & & 3145 \\
\hline
\end{tabular}

As can be seen, the presence of the ATE significantly reduced the ambient temperature capacitor resistance; a decrease in ambient temperature capacitance was also noted. 
For the capacitors with the original HTE, the average ambient temperature resistance was 156 Kohms while the average measured capacitance was 60 microfarads; leakage currents ranged from 29 to 69 microamps. At elevated temperature the average resistance was 4 ohms while the average capacitance was 794 microfarads. Leakage currents at elevated temperature ranged from 1368 to 3489 microamps.

For the capacitors that contained the ATE combined with the HTE, the average ambient temperature resistance was 337 ohms while the average ambient temperature capacitance was 48 microfarads; leakage currents ranged from 38 to 60 microamps. At elevated temperature the average resistance was 24 ohms while the average capacitance was 673 microfarads; leakage currents ranged from 553 to 3145 microfarads.

Therefore, addition of the ATE to the HTE resulted in the ambient temperature resistance decreasing from $156 \mathrm{Kohms}$ to 337 ohms. Further work is required to determine the optimum HTE:ATE ratio to use in the capacitor in order to additionally lower the ambient temperature resistance.

\subsection{DISCUSSION}

Results described above demonstrated the feasibility of fabricating a HTHV hybridized capacitor that could provide $>220$ microfarads at $100 \mathrm{~V}, 230^{\circ} \mathrm{C}$ in a compact package. This capacitor was comprised of a 2-cell stack, in which each cell utilized a $\mathrm{Ta}_{2} \mathrm{O}_{5}$ anode, a HTE$\mathrm{SiP}_{2} \mathrm{O}_{7}$ electrolyte, and a $\mathrm{RuO}_{x}$ cathode. The goals of the Phase I effort of the program were met, and a recommendation to proceed into Phase II was prepared but never submitted due to lack of a Phase II cost-share funding partner.

During the course of the program our cost-share partner informed us they were not interested in continuing on the program past the Phase I effort. Therefore a search was initiated for a new cost share partner. Over a several month period a total of 7 different capacitor companies and 2 drilling companies were contacted. Meetings were held with 3 of the capacitor companies. None of the companies decided to provide cost share, resulting in recommendation by Giner, Inc. for termination of the program at the end of Phase I.

\subsection{REFERENCES}

Baird, T., T. Fields, R. Drummond, D. Mathison, B. Langseth, A. Martin, L. Silipigno, "HighPressure, High-Temperature Well Logging, Perforating and Testing", Oilfield Review, p. 50, Summer 1998.

Evans, D.A., U.S. Patent 5,369,547 (1994).

Evans, D.A., "The Littlest Big Capacitor - An Evans Hybrid," Proceedings of The Fifth International Seminar on Double Layer Capacitors and Similar Energy Storage Devices, Deerfield Beach, Florida. (1995).

Kinard, J.T., B.J. Melody, P.M. Lessner "Electrolyte for anodizing valve metals", U.S. Patent 5,935,408 (1999).

Mallison, E.R., J.D. Rogers, B. Ohme: "High Temperature SOI CMOS Electronics Development: The Deep Trek Project," paper presented at HiTen Conference Paris, (September 6-8 2005). 


\subsection{LIST OF ACRONYMS AND ABBREVIATIONS}

$\begin{array}{ll}\mathrm{ATE} & \text { ambient temperature electrolyte } \\ \mathrm{ESR} & \text { equivalent series resistance } \\ \mathrm{H}_{2} \mathrm{SO}_{4} & \text { sulfuric acid } \\ \mathrm{HPHT} & \text { high-pressure high-temperature } \\ \mathrm{HTE} & \text { high temperature electrolyte } \\ \mathrm{HTHV} & \text { high-temperature, high-voltage } \\ \mathrm{NETL} & \text { National Energy Technology Laboratory } \\ \mathrm{RC} & \text { resistor capacitor } \\ \mathrm{RuO}_{2} & \text { ruthenium oxide } \\ \mathrm{SiP}_{2} \mathrm{O}_{7} & \text { silicon pyrophosphate } \\ \mathrm{Ta}_{2} \mathrm{O}_{5} & \text { tantalum pentoxide } \\ \mathrm{tcf} & \text { trillion cubic feet } \\ \mathrm{Ti} & \text { titanium } \\ \mathrm{Z}_{\mathrm{RE}} & \text { real impedance component } \\ \mathrm{Z} \mathrm{IM} & \text { imaginary impedance component }\end{array}$

